\title{
Comment on: "Regorafenib-Induced Hypothyroidism as a Predictive Marker for Improved Survival in Metastatic or Unresectable Colorectal Cancer Refractory to Standard Therapies: A Prospective Single-Center Study"
}

\author{
Yusuf Ziya Şener $^{1} \mathbb{D}$
}

Published online: 27 May 2020

(c) Springer Nature Switzerland AG 2020

\section{To the Editor,}

I have read with great interest the recent article published in Targeted Oncology by Kim et al. about the relationship between survival and regorafebnib induced hypothyroidism in patients with metastatic colorectal carcinoma (mCRC) [1]. The authors stated that the developmend of regorafenib induced hypothyroidism is related to improved survival.

Regorafenib is a multi- tyrosine kinase inhibitor used in the treatment of mCRC [2]. Regorafenib has several side effects including hypothyroidism, skin rash, hypertension, diarrhea, liver dysfunction, and hand-foot syndrome [1]. Thyroid hormones (TH) are key regulators of several cellular processes such as proliferation, apoptosis, differentiation, and metabolism. Previous studies have demonstrated that hypothyroidism inhibits tumor growth while hyperthyroidism causes opposite effects [3]. Computed tomography (CT) is regularly performed in cancer patients to follow up disease progression. Iodinated contrast media is used during $\mathrm{CT}$ and iodine exposure may cause hypothyroidism and this condition is termed "Wolf Chaikoff effect". It was reported that TSH concentrations may increase to up to $6.4 \mathrm{mIU} / \mathrm{L}$ in $18 \%$ of patients within 3-5 days after a CT scan. While most patients with TSH increase have subclinical hypothyriodism, some may experience overt hypothyroidism, and hypothyroidism may be permanent in a small proportion of the cases [4].

CT scans were performed 8 weeks after the start of regorafenib treatment and hypothyroidism occured in most of the patiens during second cycle [1]. Therefore; exposure to iodine may be the cause for hypothyroidism in some of the patients. I think it would be good to also assess the temporal relationship between hypothyroidism detection and CT scans.

\section{Compliance with Ethical Standards}

Funding No external funding was used in the preparation of this manuscript.

Conflict of interest Yusuf Ziya Şenern declares that he has no conflict of interest that might be relevant to the contents of this manuscript.

\section{References}

1. Kim JH, Kim SY, Kim KP, et al. Regorafenib-induced hypothyroidism as a predictive marker for improved survival in metastatic or unresectable colorectal cancer refractory to standard therapies: a prospective single-center study. Target Oncol. 2019;14(6):689-97.

2. Wilhelm SM, Dumas J, Adnane L, Lynch M, Carter CA, Schutz G, et al. Regorafenib (BAY 73-4506): a new oral multikinase inhibitor of angiogenic, stromal and oncogenic receptor tyrosine kinases with potent preclinical antitumor activity. Int J Cancer. 2011;129:245-55.

3. Hercbergs AH, Ashur-Fabian O, Garfield D. Thyroid hormones and cancer: clinical studies of hypothyroidism in oncology. Curr Opin Endocrinol Diabetes Obes. 2010;17:432-6.

4. Lee SY, Rhee CM, Leung AM, Braverman LE, Brent GA, Pearce EN. A review: Radiographic iodinated contrast mediainduced thyroid dysfunction. J Clin Endocrinol Metab. 2015;100(2):376-83.
Yusuf Ziya Şener

yzsener@yahoo.com.tr

1 Internal Medicine and Cardiology Department, Hacettepe University Faculty of Medicine, Sihhiye, Ankara, Turkey 